\section{The legend of Darwin's finches}

SIR - Mark Williamson ${ }^{1}$ has taken issue with a statement made by Peter Boag ${ }^{2}$ in his report on the Linnean Society symposium on "Evolution in the Galapagos". The statement, drawn directly from my contribution to the symposium ${ }^{3}$, is that "Darwin . . omitted any mention of the finches [of the Galapagos Islands] from his Origin of Species". Williamson points out in rebuttal that Darwin alluded indirectly to the finches in the Origin (1859) when he stressed the highly endemic nature of the Galapagos birds and fauna as a whole.

Williamson, who did not attend the Linnean Society symposium and who had not read my previously published papers on this subject (cited in Boag's report ${ }^{4}$ ), fails to mention that many of the quotations presented in proof of his contention were also cited by me - both in my symposium contribution and in my publications. Thus readers of Williamson's letter to Nature are unfortunately misled into thinking that I (and Boag) were unaware that Darwin was implicitly including the finches when discussing in general terms the birds of the Galapagos Islands.

of more significant historical importance, however, are several other misconceptions inadvertently created or perpetuated by Williamson. He claims, for example, that Darwin had already provided "sufficient detail" about the Galapagos finches in his Journal of Researches (1839, 1845 ) and that it was therefore quite unnecessary for him to cite the famous finches again in the Origin. In other words the omission of the finches from the Origin is taken as historical evidence in support of how famous these birds had become by 1859. In actual fact, not a single biologist between 1839 and 1859 (except Darwin) is known to have discussed the unusual case of Darwin's finches; and Darwin could hardly assume that readers of the Origin would, as Williamson suggests, be "well aware [like Darwin] of the importance of this famous group of birds".

Thus the point of real historical interest is why Darwin, who surely wanted to bolster the text of the Origin with his most convincing scientific evidence, chose to omit any specific reference to a group of birds that he supposedly thought were so important for his evolutionary argument. The answer to this question, discussed by me elsewhere in more detail ${ }^{5}$, is threefold. First, Darwin's island localities for his Galapagos finches were almost entirely borrowed after the Beagle voyage from the fully labelled collections of three other Beagle shipmates. Based upon this borrowed evidence, Darwin had suggested in his Journal (1845) that four (and perhaps more) of the finch species were confined to different islands. But he was rightfully distrustful of this published claim, which, being based on his inaccurately copied locality notes and insufficient collecting, was totally in error. Darwin could not therefore cite the finches in the Origin as a convincing case of evolution by geographic isolation; and he well knew it.

Second, with the exception of 2 species of Galapagos finches, Darwin mistakenly thought the remaining 11 species named by John Gould ${ }^{6}$ had identical diets. For this reason he could not argue that the finches, with their various sized beaks, were the product of evolution by natural selection, character displacement, and ensuing adaptive radiation. Other ornithologists remained in doubt on this question until David Lack's famous book Darwin's Finches turned the tide in $1947^{7}$.

Finally, Darwin was personally unconvinced that all of the Galapagos finches, particularly the warbler finch (Certhidea olivacea), were descended from just one ancestral colonist, although he had previously alluded to this possibility in his Journal (1845), in a veiled evolutionary reference. Darwin's caution was welladvised. During the remainder of the nineteenth century, ornithologists generally considered Darwin's finches to have descended from two or three different ancestors - a warbler, a ground finch, and a separate form that gave rise to the 6 species of Camarhynchus. This issue of ancestry was not resolved for 50 years after the Origin of Species was published.

It is for these three reasons that Darwin made as his paradigmatic example of evolution in the Galapagos the mockingbirds (Nesomimus - which Gould had distinguished as three species inhabiting four separate islands ${ }^{8}$ ) rather than the complex and more debatable case of the finches. Significantly, the Galapagos finches were briefly mentioned in Darwin's "Big Book" on evolution, written between 1856 and 1858. But Darwin chose to delete his speculative reference to the finches' possible common ancestry when Wallace's famous letter (1858) prompted him to abstract his manuscript down into the Origin. He evidently felt that the more general he made the Galapagos discussion (especially regarding the finches), the better off he was. Yet the legend later arose, and continues to live on, that Darwin's finches not only converted Darwin to the theory of evolution - eureka-like - but also "deservedly held a prideful place in the Origin"9.

\section{Department of Psychology,}

\section{University College, London WC1, UK}

1. Williamson, M. Nature 302, 566 (1983).

2. Boag, P.T. Nature 301, 12 (1983).

3. Sulloway, F.J. in Evolution in the Galapagos (ed. Berry, R.J.), Biol. J. Linn. Soc. 21, (in the press)

4. Sulloway, F.J. J. hist. Biol. 15, I (1982); Bull. Br. Mus. nat. Hist. (Zool.) 43, 49 (1982).

5. Sulloway, F.J. J. hist. Biol. 15, 325 (1982).

6. Gould, J. Proc. Zool. Soc. Lond. 5,4 (1837).

7. Lack, D. Darwin's Finches (Cambridge University Press, 1947).

8. Gould, J. Proc. Zool. Soc. Lond. 5, 27 (1837).

9. Ruse. M. Darwinism Defended, 115 (Addison-Wesley, Reading, Massachuset(s, 1982).

\section{Solar constant}

SIR - In their review "Changes in the solar constant and climatic effects", Eddy et al. ' raise the issue of whether the sunspotassociated irradiance dips now seen in satellite radiometry were detectable in the Smithsonian (APO) ground-based radiometry carried out between 1923 and 1952. Two recent analyses of the APO data (still the longest set of solar constant data) reach opposite conclusions.

The point of view put forward by Eddy et $a l$. was that the solar irradiance changes caused by magnetic activity were too small to be detectable in the APO data. This conclusion was based on the extensive analysis by $\mathrm{Hoyt}^{2}$, which found no significant evidence for an irradiance modulation by solar activity in the APO solar constant values. A different conclusion was reached in a separate study of the APO data base by Foukal et al. ${ }^{3,4}$ providing evidence for a short-term modulation of irradiance by spots and faculae at a combined r.m.s. level of $5-7 \times 10^{-4}$.

A number of considerations should be weighed in evaluating this disagreement. On one hand, Hoyt's analysis has shown that a substantial fraction (20-50 per cent) of the total variance seen in the APO data can be attributed to inadequate correction for atmospheric aerosols and dust. His analysis also showed that caution must be exercised in deriving confidence limits from that database, since straightforward tests for the influence of spots on irradiance measured at different APO field stations can yield contradictory results at similar levels of formal significance.

On the other hand, the modulation reported by Foukal et al. is at a level below 10 per cent of the total variance of the APO irradiances, so its presence is not excluded by the finding that 20-50 per cent of the total variance is atmospheric noise. We note also that the irradiance increase with facular area, irradiance decrease with spot area, and the combined level of 28 day irradiance modulation by magnetic activity, are three independent results of the Foukal et al. study. Their good agreement in sign and amplitude with recent results of radiometry from the Solar Maximum Mission and Nimbus-7 deserves attention.

It is still unclear whether or not C.G. Abbot's epic measurement programme detected real solar irradiance variations. The evidence for both points of view is presented in the publications cited below.

PETER FOUKAL
DOUGLAS HOYT
Atmospheric and Environmental
Research Inc.,
Cambridge, Massachusetts, and National
Center for Atmospheric Research,
Boulder, Colorado, USA

. Eddy, J.A., Gilliland, R.1.. \& Hoyı, V.H. Nature 300. 689-693 (1982).

2. Hoy, D. Rev. Geophys. Space Phys. 17, 427-458 (1979).

3. Foukal, P..Vernazza, J. Astrophys. J. $215952-959$ (1977). 4. Foukal, P. \& Vernazza, J. Astrophys. J. 234, 707-715 (1979). 